\title{
Photosynthetic characteristics and chlorophyll $a$ fluorescence induction parameters in elite clone (GS1) of Pinus sylvestris var. mongolica
}

\author{
P. MENG ${ }^{* * *,+}$ and G.C. YOU** \\ Qingdao Agricultural University, 266000 Qingdao, Shandong Province, China* \\ Liaoning Province Sand-Fixation and Afforestation Research Institute, 123000 Fuxin, Liaoning Province, China**
}

\begin{abstract}
We selected the elite clone of Pinus sylvestris var. mongolica 'GS1' from 365 clones in a primary seed orchard in Liaoning Province, China. To understand the photosynthesis characteristics and mechanisms, 40-year-old 'GS1' trees were compared with a common clone 'H524' of the same age at the same seed orchard. Results showed that 'GS1' had higher net photosynthetic rate because of higher stomatal conductance $\left(g_{\mathrm{s}}\right)$; the larger external and inner diameters of stomata were the structural factors enabling maintenance of higher $g_{\mathrm{s}}$. The higher light-saturated net photosynthetic rate of 'GS1' was mainly due to higher electron transfer activity, demonstrated by the lower relative fluorescence intensity from O-step to P-step. The increase in density of active reaction centers resulted in an increase in energy flux per cross section, which led to higher photosynthetic performance.
\end{abstract}

Additional key words: JIP-test; light-response parameter; relative variable fluorescence; stomata size.

\section{Introduction}

Photosynthesis involves the conversion of light energy into chemical energy, using two photosystems and carbon fixation enzymes to oxidize water to molecular oxygen and to reduce $\mathrm{CO}_{2}$ to carbohydrate (Blankenship 2014, Govindjee et al. 2017). It is, therefore, the most important physiological process providing the material basis of plant growth and development (McGarvey et al. 2004). The light reaction of photosynthesis consists of light harvesting, energy conversion, electron transport, and proton transfer, while dark reaction includes enzymatic reactions and carbon fixation (Kiirats et al. 2010, Li et al. 2015). Light reaction is the energy source for the dark reaction, so it is very important to understand the process. The light energy absorbed by photosynthetic pigments has two other fates: loss by internal conversion (as heat) or as light emission (mostly fluorescence). Chlorophyll (Chl) $a$ fluorescence analysis is a kind of 'intrinsic probe' used in light reaction research. Compared to the 'superficial' gas exchange index, Chl $a$ fluorescence parameters have the characteristics reflecting 'endogenicity' and can provide valuable information on the structure and function of the photosynthetic apparatus (Krause et al. 1991, Papageorgiou and Govindjee 2004). The Chl $a$ fluorescence transients
(O-J-I-P curve) obtained during continuous excitation can fully reflect the light reaction process, efficiency, and structure of the protein complex of PSII located on thylakoid membrane. The typical O-J-I-P curve often has $\mathrm{O}-$, J-, I-, and P-steps, etc. Here, O represents the darkadapted minimum fluorescence, $\mathrm{F}_{0} ; \mathrm{J}$ and $\mathrm{I}$ indicate the two inflections at $2 \mathrm{~ms}$ and $30 \mathrm{~ms}$; $\mathrm{P}$ indicates $\mathrm{F}_{\mathrm{m}}$ when the fluorescence is maximal, which is usually in the $\sim 500$-ms range) (Stirbet and Govindjee 2012, Stirbet et al. 2014). Through the fluorescence characteristics of these steps, we can evaluate the quantum efficiency of electron transfer process and effectively monitor plant photosynthetic performance under nondestructive conditions (Demmig-Adams and Adams 1996, Zhang et al. 2009); this method is known as the JIP-test (Mereu et al. 2011). This test is convenient, rapid, and sensitive, and can be applied in vivo and in vitro without limitation in terms of material size and morphology (Stirbet and Govindjee 2011). This technique has been used to study the intrinsic photosynthesis mechanism in some pine species (Qiu et al. 2013, Meng et al. 2016).

Pinus sylvestris var. mongolica, native to the Daxinganling Mountains and Hulunbeir grassland, northeastern China, is a geographical variety of Scots pine (P. sylvestris) distributed to the Far East. After several decades of introduction and afforestation, the tree species has formed a

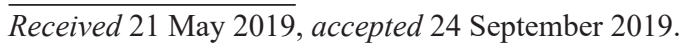

+Corresponding author; e-mail: mengpeng18@163.com

Abbreviations: DBH - diameter at breast height; DS - diameter of stomata; $\mathrm{F}_{0}$ - minimal fluorescence yield of the dark-adapted state; $\mathrm{F}_{\mathrm{m}}$ - maximal fluorescence yield of the dark-adapted state; $g_{\mathrm{s}}-$ stomatal conductance; I-step - Chl $a$ fluorescence at $\sim 30 \mathrm{~ms} ; \mathrm{J}$-step Chl $a$ fluorescence at $\sim 2 \mathrm{~ms}$; K-step - Chl $a$ fluorescence at $\sim 0.3 \mathrm{~ms}$; L-step - Chl $a$ fluorescence at $\sim 0.1 \mathrm{~ms}$; LCP - light-compensation point; LSP - light-saturation point; NADP - nicotinamide adenine dinucleotide phosphate; $P_{\mathrm{N}}-$ net photosynthetic rate; $P_{\mathrm{Nmax}}-$ lightsaturated net photosynthetic rate; $\mathrm{PQ}$ - plastoquinone; RH - air relative humidity; SD - stomatal density; STV - individual stand tree volume; $\mathrm{T}_{\text {air }}$ - air temperature; $\mathrm{VPD}$ - vapor pressure deficit.

Acknowledgements: Authors are grateful to National Natural Science Foundation of China (31770675) and National Key R\&D Program of China (2017YFD0600505). 
large area of artificial forest in the 'three North' areas of China. It shows excellent characteristics, such as drought resistance, cold tolerance, and barren soil tolerance. In order to develop better this species and continuously improve its genetic quality and seed yield, the Liaoning Province SandFixation and Afforestation Research Institute (LPSFARI) completed construction of $66.7 \mathrm{hm}^{2}$ of primary seed orchard including 365 clones and $5 \mathrm{hm}^{2}$ of half-sib progeny determination forest in Zhanggutai sandy land, Zhangwu County, Liaoning Province, China, from the mid-1970s to the early 1990s. The growth and seed yield of the mother tree and the growth performance of the half-sib progeny were investigated, and the best clone was selected and named 'GS1'. At the same time, the common clone 'H524', which represented the average growth state of all clones in the seed orchard, was also selected.

Studies of the photosynthetic properties and Chl $a$ fluorescence characteristics in $P$. sylvestris have been reported. The majority have been carried out at high latitudes and cold regions, mostly in northern Europe (Hari et al. 1981, Kellomäki and Wang 1998, Šiffel and Šantrůček 2005, Mellander et al. 2008), but few studies have been done in mid-latitudes. These studies indicate that the 'midday break' phenomenon usually occurs during the diurnal variation in photosynthesis of $P$. sylvestris at both seedling stage and forest-formation stage, and that photosynthesis in this species is often more effective in the early morning than later in the day. The concentration of PSII reaction centers (RC) - which are composed of D1 protein, together with D2 protein and cytochrome $b_{559}-$ was closely related to the intensity of photosynthesis. The concentration decreased significantly during overwintering, mainly due to the decrease in D1 protein, which fell to $90 \%$ by December (Ottander et al. 1995). Studies of the photosynthetic characteristics of $P$. sylvestris var. mongolica have mainly focused on the seedling stage, and not on trees more than 20 years old. Ding et al. (2011) and Wu et al. (2003) studied the photosynthetic characteristics of this species at mature forest stage in sandy land. Most primary seed orchards of $P$. sylvestris var. mongolica in China have almost entered the mature forest stage, but the selection of excellent clones such as 'GS1' is rare, and the comparative study of photosynthetic characteristics among clones has been rarely reported.

In this study, the common clone 'H524' was used as control (CK), to investigate comparatively the growth and stomatal morphology indexes of 'GS1' at a mature forest stage. The photosynthetic indexes of these two clones were compared by means of the JIP-test, to allow a fundamental understanding of the photosynthetic mechanism of ' $\mathrm{GS} 1$ ', and provide a theoretical basis for the popularization and application of this fine clone in sandy lands.

\section{Materials and methods}

Site description: The experiment was carried out in the primary seed orchard of $P$. sylvestris var. mongolica $(5 \times 5 \mathrm{~m})$ in sandy land, located at Zhanggutai $\left(42^{\circ} 43^{\prime} \mathrm{N}\right.$, $122^{\circ} 29^{\prime} \mathrm{E}$, altitude $226.5 \mathrm{~m}$ ), Zhangwu County, Liaoning province, China. Mean annual precipitation for this area is $433 \mathrm{~mm}$, mean evaporation is $1,570 \mathrm{~mm}$, mean annual temperature is $6.7^{\circ} \mathrm{C}$, frost-free period is $154 \mathrm{~d}, \geq 10^{\circ} \mathrm{C}$ effective accumulated temperature is $2,800-3,200^{\circ} \mathrm{C}$. This area belongs to the semiarid region of the northern China, and soil in this area is sandy and formed from river alluvium, the depth of the sand layer is about $30 \mathrm{~m}$.

Plant material: Two plots containing nine trees of 40-yearold 'GS1' and 'H524' (CK), respectively, were selected in a primary seed orchard of $P$. sylvestris var. mongolica, about $100 \mathrm{~m}$ apart from each other. The site conditions and water-fertilizer management were the same. The tree height (TH $[\mathrm{m}])$ and diameter at breast height (DBH $[\mathrm{cm}])$ of each tree were measured in the two plots, and the individual stand tree volume ( $\mathrm{STV}\left[\mathrm{m}^{3}\right]$ ) was calculated according to equation (1). Three 'GS1' and CK standard trees were selected on the basis of average $\mathrm{DBH}$ and $\mathrm{TH}$, respectively.

$\mathrm{STV}=0.000115923 \mathrm{TH}^{0.625068016} \mathrm{DBH}^{1.917025106}$

Net photosynthetic rate $\left(\boldsymbol{P}_{\mathrm{N}}\right)$ and influencing factors: $P_{\mathrm{N}}$ and its influencing factors were measured in late May (the initial growth stage) and late July 2018 (the middle growth stage). Sample branches exposed to the south and of uniform thickness were selected from the middle of the crown of the 'GS1' and CK trees, and the Li-6400 photosynthesis system ( $\mathrm{Li}$-Cor, Lincoln, NE, USA) was used to determine the diurnal variation in $P_{\mathrm{N}}$ in a natural state. $\mathrm{CO}_{2}$ concentrations were in the range $390-410 \mu \mathrm{L} \mathrm{L}^{-1}$, air temperature $\left(\mathrm{T}_{\text {air }}\right)$ was in the range $22-26^{\circ} \mathrm{C}$, and air relative humidity $(\mathrm{RH})$ was in the range $10-80 \%$. Before the measurement, the air flow rate was set at $1,000 \mu \mathrm{mol} \mathrm{s}^{-1}$ to correct the instrument and then it was set to $500 \mu \mathrm{mol} \mathrm{s}$ during the measurement. Sunny days were chosen for the determination, $3 \mathrm{~d}$ a month, from 8:00 to 19:00 h every day, and each determination was made every $1 \mathrm{~h}$. The adjacent ten needles, whose lengths and widths were in the mean state, were selected and marked for continuous measurement at different time points. These ten needles were tiled in the cuvette along its wide edge (the area of the cuvette was $6 \mathrm{~cm}^{2}$ ). The needles in the cuvette were photographed vertically with a digital camera (Canon, Tokyo, Japan) to form a bitmap (.bmp) photograph, which was used to determine photosynthetic leaf area by image analysis system 10.0 software (Yilong Xinke, Beijing, China). $P_{\mathrm{N}}$ values were converted according to the measured leaf area. $\mathrm{T}_{\text {air, }} \mathrm{RH}$, vapor pressure deficit (VPD), and stomatal conductance $\left(g_{\mathrm{s}}\right)$ were recorded simultaneously.

The stomatal shape and density on the abaxial surface of the needles of ' $\mathrm{GS} 1$ ' and $\mathrm{CK}$ in the middle growing stage (late July) were observed by scanning electron microscopy (SEM, JSM 65/0, Shimadzu, Tokyo, Japan), and at that time the needles of both clones were mature and $7.5 \mathrm{~cm}$ in length. The needles were rinsed with distilled water, dried, and crosscut out a strip $0.5 \mathrm{~cm}$ long in the middle part of them. Conductive adhesive was pasted onto upper surface of a 1-cm-diameter copper cylinder, and then three needle strips for one clone were stuck to the conductive adhesive. After the samples were sprayed with 
gold for $1 \mathrm{~min}$, they were fixed and observed in the SEM observation room.

Light-response measurement and parameter calculation: The light-response characteristics of the two clones were measured at about 10:00 $\mathrm{h}$ following the diurnal measurement in $P_{\mathrm{N}}$ variation, when photosynthesis of the needles was fully activated and $P_{\mathrm{N}}$ was at its peak value. Under conditions of normal atmospheric $\mathrm{CO}_{2}$ concentrations, an optimum $\mathrm{RH}$ range $(70 \pm 5 \%)$, and a controlled temperature $\left(25 \pm 0.5^{\circ} \mathrm{C}\right)$, the $P_{\mathrm{N}}$ of needles under different PPFD was determined by the Li-6400 photosynthesis system. Using an LED light source ( $\mathrm{Li}$-Cor, Lincoln, NE, USA) mounted on the leaf chamber, PPFD were set at 2,$000 ; 1,800 ; 1,500 ; 1,200 ; 1,000 ; 800,500$,

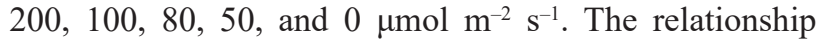
between $P_{\mathrm{N}}$ and PPFD was fitted using equation (2) by the SPSS v. 13.0 (IBM, New York, USA) nonlinear module (Meng et al. 2016):

$P_{\mathrm{N}}=P_{\mathrm{N} \max }\left(1-C_{0} e^{\frac{-\alpha P \text { P } \mathrm{N} \max }{P}}\right)$

where $P_{\mathrm{Nmax}}$ is the maximum net photosynthetic rate, $\alpha$ is the light quantum utilization efficiency under weak light (that is apparent quantum efficiency), and $C_{0}$ is a measure of net photosynthetic rate approaching zero under weak light. Through the fitness test, if the fitting effect of the equation was good, then equation (3) was used to calculate the light-compensation point (LCP):

$$
\mathrm{LCP}=\frac{P_{\mathrm{Nmax}} \ln \left(C_{0}\right)}{\alpha}
$$

The PPFD in which $P_{\mathrm{N}}$ reaches $99 \%$ of $P_{\mathrm{N} \max }$ is assumed to be the light-saturation point (LSP), and equation (4) was used to calculate LSP:

$$
\mathrm{LSP}=\frac{P_{\mathrm{Nmax}} \ln \left(100 C_{0}\right)}{\alpha}
$$

Determination of $\mathrm{Chl} \boldsymbol{a}$ fluorescence induction parameters: Measurements were made at 10:00 h using a pocket plant efficiency analyzer (PEA) (Pocket PEA, Hansatech Instrument Ltd., UK). The healthy needles to be measured on the sample branches were arranged in parallel in the leaf clip, completely covering the $4-\mathrm{mm}^{2}$ test hole, and the leaf clip switch was shut off, so that the local measuring point of the tested needles was kept under dark adaptation for 20 min. Pocket PEA has six LEDs that can provide red light at $650 \mathrm{~nm}$, and the light intensity was 3,500 $\mu \mathrm{mol}$ (photon) $\mathrm{m}^{-2} \mathrm{~s}^{-1}$. The Chl $a$ fast phase fluorescence (O-J-I-P) curve takes the time as the transverse coordinate, and the original fluorescence value (minimum fluorescence, $\mathrm{F}_{0}$; maximum fluorescence, $\mathrm{F}_{\mathrm{m}}$ ) as the longitudinal coordinate. To compare the differences between the two clones and overcome the shortcomings of large variability in the original O-J-I-P curve, it was necessary to standardize the original curve. We used $F_{m}-F_{0}$ for standardization. The standardized fluorescence signal data were expressed by relative variable fluorescence $\left(\mathrm{V}_{\mathrm{t}}\right), \mathrm{V}_{\mathrm{t}}=\left(\mathrm{F}_{\mathrm{t}}-\mathrm{F}_{0}\right) /\left(\mathrm{F}_{\mathrm{m}}-\mathrm{F}_{0}\right)$.
In this standardized curve, the fluorescence intensity of O-step was 0, and that of P-step was 1 (Zeliou et al. 2009).

The physiological significance of the main fluorescence parameters obtained from the O-J-I-P curve was analyzed according to Stirbet et al. (2018), where $\mathrm{O}$ is origin (the minimum fluorescence $\mathrm{F}_{0}$ ), $\mathrm{J}$ and $\mathrm{I}$ are for two intermediate levels at $2 \mathrm{~ms}$ and $30 \mathrm{~ms}\left(\mathrm{~F}_{\mathrm{j}}\right.$ and $\left.\mathrm{F}_{\mathrm{i}}\right)$, and $\mathrm{P}$ is peak $\left(\mathrm{F}_{\mathrm{m}}\right.$, when the fluorescence is maximal). ABS, RC, TR, ET, DI, CS, and PI are abbreviations for absorbance, reaction center, trapping, electron transport, dissipation, cross section, and performance index, respectively.

In addition to selecting some technical parameters, which can reflect the efficiency and quantum yield, our study also selected specific activity parameters and performance parameters to analyze the 'fast' $(<1 \mathrm{~s}) \mathrm{Chl} a$ fluorescence transient. Specific active parameters can reflect more accurately the absorption, conversion, and dissipation of the light energy in the photosystem of a plant (Li et al. 2015). The performance indexes $\left(\mathrm{PI}_{\mathrm{ABS}}, \mathrm{PI}_{\mathrm{CSo}}\right.$, $\mathrm{PI}_{\mathrm{CSm}}$ ) calculated contain three independent parameters $\left(\mathrm{RC} / \mathrm{CS}, \varphi_{\mathrm{P} 0}\right.$, and $\left.\psi_{\mathrm{E} 0}\right)$, so the performance indexes can fully and accurately reflect the state of the photosystem (Strasser et al. 2004, Van Heerden et al. 2004). All the parameters with their meaning are listed in Appendix.

Statistical analysis: All data were analyzed using SPSS v. 13.0 software, and data between groups were subjected to one-way analysis of variance (ANOVA) and to Fisher's least significant difference (LSD) multiple comparison test $(P<0.05)$. The figures in this study were drawn with Excel 2007 software.

\section{Results}

Growth: Although there was no significant difference in $\mathrm{TH}$, the average DBH and individual STV of 'GS1' were significantly higher than that of CK, which were $35.675 \mathrm{~cm}$ and $0.479 \mathrm{~m}^{3}$, respectively, 1.48 times and 2.27 times those of CK (Table 1).

The diurnal course of $\boldsymbol{P}_{\mathrm{N}}$ : At the initial growth stage, $P_{\mathrm{N}}$ of ' $\mathrm{GS} 1$ ' was slightly higher than that of $\mathrm{CK}$, and there were two peaks with a smaller second peak value. Its first peak value was $7.066 \mu \mathrm{mol} \mathrm{m} \mathrm{m}^{-2} \mathrm{~s}^{-1}$ appearing at 9:00 h, then it decreased rapidly, and reached a low level at 12:00 $\mathrm{h}$. Then it increased slightly, and the second peak of $1.57 \mu \mathrm{mol} \mathrm{m} \mathrm{m}^{-2} \mathrm{~s}^{-1}$ appeared, which was only $20.9 \%$ of the first peak and appeared at 14:00 $\mathrm{h}$ in the afternoon (Fig. $1 A) . P_{\mathrm{N}}$ of $\mathrm{CK}$ was lower and the diurnal variation exhibited single peak at 10:00 h, and its maximum value was $6.534 \mu \mathrm{mol} \mathrm{m} \mathrm{m}^{-2} \mathrm{~s}^{-1}$, and then gradually decreased. After 13:00 h, it approached to zero. After 18:00 h, $P_{\mathrm{N}}$ of both clones were less than zero and that of $\mathrm{CK}$ was more negative, i.e., $-1.693 \mu \mathrm{mol} \mathrm{m}{ }^{-2} \mathrm{~s}^{-1}$.

At the middle growth stage, shape of the photosynthetic diurnal variation curves of 'GS1' and CK did not change, i.e., the number of peaks did not change. The peak and valley values for both clones increased, especially the valley value and the second peak value $\left(3.524 \mu \mathrm{mol} \mathrm{m} \mathrm{m}^{-2} \mathrm{~s}^{-1}\right)$ of 'GS1' were larger, and its second peak was $46.3 \%$ of 
Table 1. Growth investigation of Pinus sylvestris var. mongolica clones 'GS1' and 'H524' (CK). TH - tree height, DBH - diameter at breast height, STV - individual stand tree volume. Different lowercase letters mean significant difference between the two clones at 0.05 level. Mean $\pm \operatorname{SD}(n=9)$.

\begin{tabular}{lllll}
\hline Clone & Age [years] & \multicolumn{1}{c}{ TH $[\mathrm{m}]$} & DBH $[\mathrm{cm}]$ & STV $\left[\mathrm{m}^{3}\right]$ \\
\hline GS1 & 40 & $10.575 \pm 0.247^{\mathrm{a}}$ & $35.675 \pm 1.050^{\mathrm{a}}$ & $0.479 \pm 0.025^{\mathrm{a}}$ \\
CK & 40 & $9.980 \pm 0.472^{\mathrm{a}}$ & $23.650 \pm 0.832^{\mathrm{b}}$ & $0.211 \pm 0.022^{\mathrm{b}}$ \\
\hline
\end{tabular}

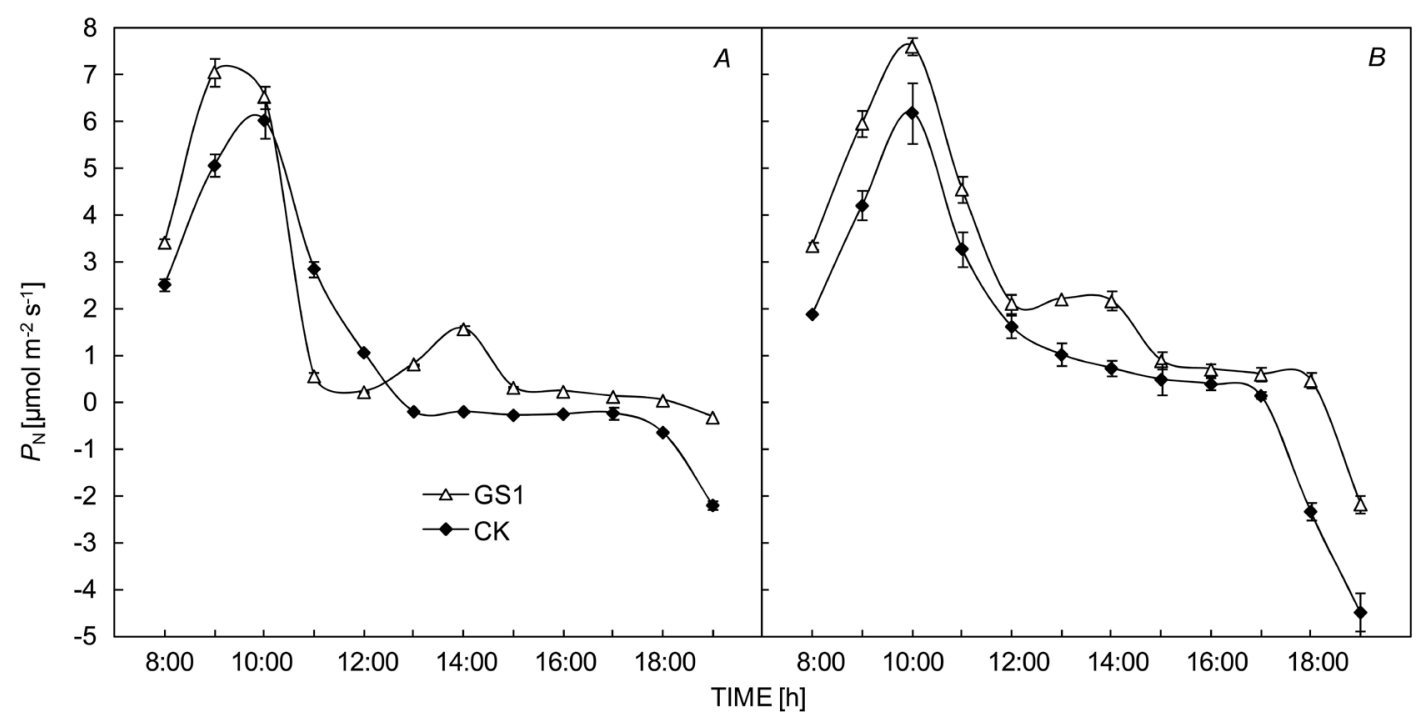

Fig. 1. Diurnal changes of net photosynthetic rate $\left(P_{\mathrm{N}}\right)$ in Pinus sylvestris var. mongolica clones 'GS1' and 'H524' $(\mathrm{CK})$ at initial $(A)$ and middle $(B)$ growth stages (mean $\pm \mathrm{SE}, n=9)$.

the first peak (Fig. 1B). In addition, its first peak appeared at 10:00 $\mathrm{h}$ delayed by $1 \mathrm{~h}$ compared to the initial growth stage, and negative value appeared after 18:00 h, it was $-2.173 \mu \mathrm{mol} \mathrm{m}{ }^{-2} \mathrm{~s}^{-1}$. The negative value of CK appeared at 17:00 $\mathrm{h}$ and decreased to $-3.983 \mu \mathrm{mol} \mathrm{m} \mathrm{m}^{-2} \mathrm{~s}^{-1}$.

Main factors influencing the $\boldsymbol{P}_{\mathrm{N}}$ : Table 2 showed that the $g_{\mathrm{s}}$ positively affected the $P_{\mathrm{N}}$ of ' $\mathrm{GS} 1$ ' and CK; especially for 'GS1', the correlation coefficient $(R)$ was $0.5120(\mathrm{~K}=30$, $\left.>R_{0.01}\right) . \mathrm{T}_{\text {air }}, \mathrm{RH}$, and VPD had great influence on $P_{\mathrm{N}}$ of 'GS1', and the correlation coefficient between RH and $P_{\mathrm{N}}$ was significantly positive, which was as high as 0.5894 $\left(\mathrm{K}=30,>R_{0.001}\right)$. The correlation coefficients of $\mathrm{T}_{\text {air }}$ and VPD were $-0.6203\left(\mathrm{~K}=30,>R_{0.001}\right)$ and $-0.5457(\mathrm{~K}=30$, $\left.>R_{0.01}\right)$, respectively. There was no significant correlation between the above three meteorological factors and $P_{\mathrm{N}}$ of CK.

As shown in Table 3, the average $P_{\mathrm{N}}$ and $g_{\mathrm{s}}$ of 'GS1' during the study period were $1.957 \mu \mathrm{mol} \mathrm{m} \mathrm{m}^{-2} \mathrm{~s}^{-1}$ and $30.691 \mathrm{mmol} \mathrm{m}^{-2} \mathrm{~s}^{-1}$, which were 1.23 and 2.12 times higher than those of $\mathrm{CK}$, respectively. From the aspect of stomatal characteristics (Table 3, Fig. 2), the stomatal density (SD) of ' $G S 1$ ' was slightly higher than that of $\mathrm{CK}$, but there was no significant difference between them, and both were about $80 \mathrm{~mm}^{-2}$. However, the external and inner DS of 'GS1' were 37.983 and $24.454 \mu \mathrm{m}$, respectively, which were significantly higher than those of CK.

Determination of light-response parameters: Under the conditions when other environmental factors are relatively stable, the light-response curve reflects the variation of $P_{\mathrm{N}}$ with the change of PPFD. By using formula (2), the light-response curves of 'GS1' and CK at the initial growth stage were fitted as follows:

$$
\begin{aligned}
& \text { 'GS1': } P_{\mathrm{N}}=7.415 \times\left(1-1.149 e^{\frac{-0.067 P P F D}{7.415}}\right)\left(R^{2}=0.918\right) \\
& \mathrm{CK}: P_{\mathrm{N}}=6.875 \times\left(1-1.120 e^{\frac{-0.062 P P F D}{6.875}}\right)\left(R^{2}=0.931\right)
\end{aligned}
$$

And the light-response curves of ' $\mathrm{GS} 1$ ' and $\mathrm{CK}$ at the middle growth stage were fitted as follows:

$$
\text { 'GS1': } P_{\mathrm{N}}=9.004 \times\left(1-1.394 e^{\frac{-0.014 P P F D}{9.004}}\right)\left(R^{2}=0.884\right)
$$

$$
\mathrm{CK}: P_{\mathrm{N}}=7.342 \times\left(1-1.825 e^{\frac{-0.025 P P F D}{7.342}}\right)\left(R^{2}=0.814\right)
$$

Since the number of samples was 60 (i.e., five data points under each PPFD), the above fitting values show that all light-response curve equations were good enough to obtain meaningful light-response parameters (Table 4). The $P_{\text {Nmax }}$ of 'GS1' and CK were 9.004 and $7.342 \mu \mathrm{mol}$ $\mathrm{m}^{-2} \mathrm{~s}^{-1}$, respectively, at the middle growth stage, and were higher than those at initial growth stage. The LSP and lightcompensation point (LCP) of the two clones also greatly 
Table 2. Correlation coefficients between photosynthetic rate and influence factors of Pinus sylvestris var. mongolica clones 'GS1' and 'H524' (CK). Tair - air temperature, $\mathrm{RH}-$ atmospheric humidity, VPD - vapor pressure deficit, $g_{\mathrm{s}}-$ stomatal conductance. $\mathrm{K}=30$, ${ }^{*}-R_{0.01} \geq R>R_{0.05},{ }^{* *}-R_{0.001} \geq R>R_{0.01},{ }^{* * *}-R>R_{0.001}$.

\begin{tabular}{lllll}
\hline Clone & $\mathrm{T}_{\text {air }}\left[{ }^{\circ} \mathrm{C}\right]$ & $\mathrm{RH}[\%]$ & $\mathrm{VPD}\left[\mathrm{mg} \mathrm{L}^{-1}\right]$ & $g_{\mathrm{s}}\left[\mathrm{mmol} \mathrm{m}^{-2} \mathrm{~s}^{-1}\right]$ \\
\hline $\mathrm{GS} 1$ & $-0.6203^{* * *}$ & $0.5894^{* * *}$ & $-0.5457^{* *}$ & $0.5120^{* *}$ \\
$\mathrm{CK}$ & -0.1460 & 0.1826 & -0.2554 & $0.4378^{*}$ \\
\hline
\end{tabular}

Table 3. Comparison of net photosynthetic rate $\left(P_{\mathrm{N}}\right)$, stomatal conductance $\left(g_{\mathrm{s}}\right)$, and stomatal characteristics of Pinus sylvestris var. mongolica clones 'GS1' and 'H524' (CK). The values are means \pm SD from overall measurements at the initial and middle growth stages, different lowercase letters mean significant difference between the two clones at 0.05 level. SD - stomatal density, DS - diameter of stomata.

\begin{tabular}{llllll}
\hline Clone & $P_{\mathrm{N}}\left[\mu \mathrm{mol} \mathrm{m}^{-2} \mathrm{~s}^{-1}\right]$ & $g_{\mathrm{s}}\left[\mathrm{mmol} \mathrm{m}^{-2} \mathrm{~s}^{-1}\right]$ & $\mathrm{SD}\left[\mathrm{mm}^{-2}\right]$ & External DS $[\mu \mathrm{m}]$ & Inner DS $[\mu \mathrm{m}]$ \\
\hline GS1 & $1.957 \pm 0.375^{\mathrm{a}}$ & $30.691 \pm 4.925^{\mathrm{a}}$ & $88 \pm 10^{\mathrm{a}}$ & $37.983 \pm 4.334^{\mathrm{a}}$ & $24.454 \pm 3.428^{\mathrm{a}}$ \\
CK & $1.594 \pm 0.568^{\mathrm{b}}$ & $14.485 \pm 5.316^{\mathrm{b}}$ & $73 \pm 11^{\mathrm{a}}$ & $33.416 \pm 3.325^{\mathrm{b}}$ & $18.012 \pm 1.174^{\mathrm{b}}$ \\
\hline
\end{tabular}

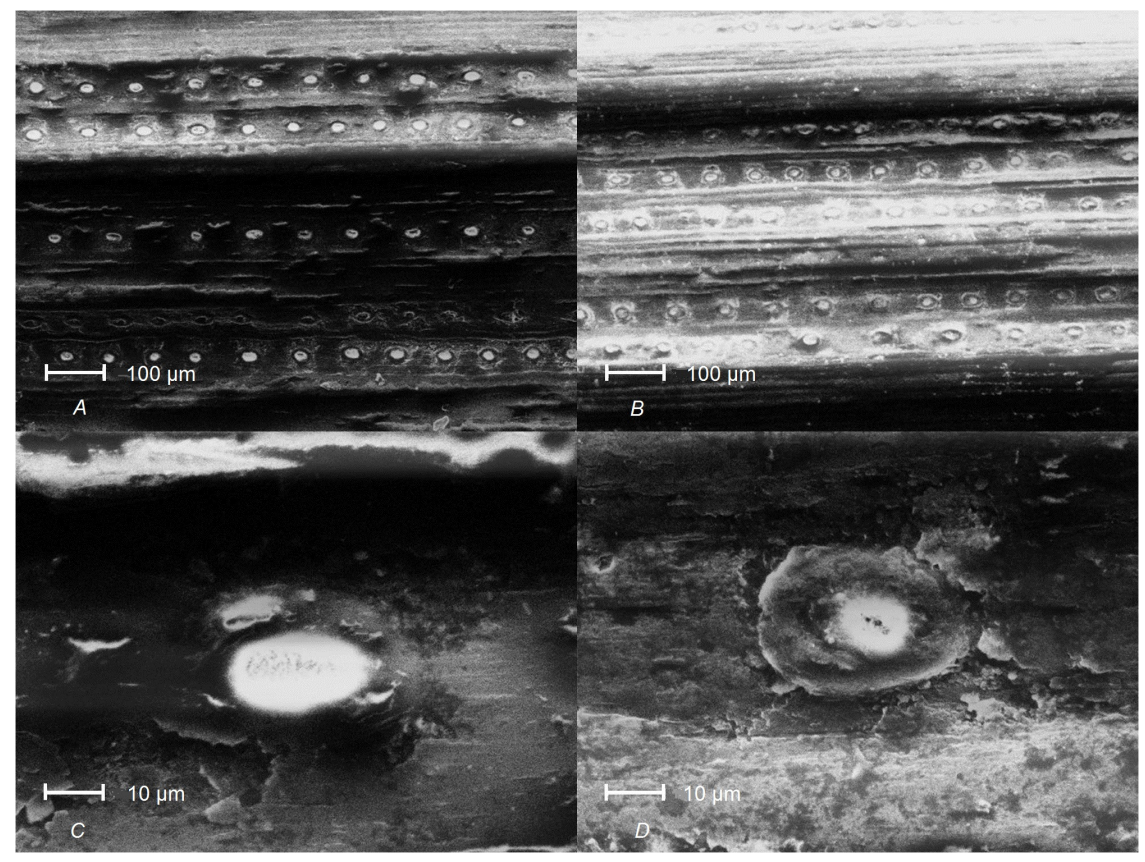

Fig. 2. Stomatal morphology of Pinus sylvestris var. mongolica clones ' $\mathrm{GS1}$ ' $(A, C)$ and 'H524' $(\mathrm{CK})(B, D)$ under scanning electron microscopy. increased at the middle growth period. There was no significant difference in the above three indexes between the two clones at the initial growth stage. However, at the middle growth stage, $P_{\mathrm{Nmax}}$ and LSP of 'GS1' were 1.23 and 2.08 times those of $\mathrm{CK}$, respectively, although there was no significant difference in LCP between them.

O-J-I-P curve: As shown in the O-J-I-P curve, at the initial growth stage, there was a small difference between the relative variable fluorescence $\left(\mathrm{V}_{\mathrm{t}}\right)$ of ' $\mathrm{GS} 1$ ' and $\mathrm{CK}$ (Fig. 3A). To observe more clearly the difference of fluorescence in different steps, especially at the J-step, which is involved in the calculation of various specific activity parameters of Chl $a$ fluorescence (Stirbet et al. 2018), the O-J-I-P curve drawn by $\mathrm{V}_{\mathrm{t}}$ of 'H524' was used as a control, then the normalized fluorescence difference
$\left(\Delta \mathrm{V}_{\mathrm{t}}\right)$ between the 'GS1' curve and the control curve was used to redraw the figure. It was more obvious from the new figure (Fig. $3 B$ ) that the $\mathrm{V}_{\mathrm{t}}$ of ' $\mathrm{GS} 1$ ' in J-step was lower, which indicated that the electron transfer activity from $\mathrm{Q}_{\mathrm{A}}$ to $\mathrm{Q}_{\mathrm{B}}$ was higher than that of $\mathrm{CK}$. However, $\mathrm{V}_{\mathrm{t}}$ of ' $\mathrm{GS} 1$ ' in I-step was relatively high, indicating that the electron transport activity from $\mathrm{Q}_{\mathrm{B}}$ to PSI was slightly lower than that of CK. Fig. 3 also showed that the time of reaching P-step for ' $\mathrm{GS} 1$ ' was longer than that of $\mathrm{CK}$.

At the middle growth stage, the $\mathrm{V}_{t}$ of ' $\mathrm{GS} 1$ ' was significantly different from that of CK (Fig. 3C), showing a lower $\mathrm{V}_{\mathrm{t}}$ value from $\mathrm{O}$ - to $\mathrm{P}$-step, especially in the $\mathrm{J}$ and I-step, the maximum difference occurring between the two steps, up to 0.13. It was shown that the electron transfer activity in ' $\mathrm{GS1}$ ' across the $\mathrm{Q}_{\mathrm{A}}$ and $\mathrm{Q}_{\mathrm{B}}$ to the PSI was significantly higher than that in CK (Fig. 3D). 
Table 4. Light-response parameters of Pinus sylvestris var. mongolica clones 'GS1' and 'H524' (CK). Different uppercase letters mean significant difference between the two growth stages for the same clone and different lowercase letters mean significant difference between the two clones at the same growth stage at 0.05 level. $P_{\mathrm{Nmax}}-$ light-saturated net photosynthetic rate, LSP - light-saturation point, LCP - light-compensation point.

\begin{tabular}{lllcr}
\hline Clone & Growth stage & $P_{\text {Nmax }}\left[\mu \mathrm{mol} \mathrm{m}{ }^{-2} \mathrm{~s}^{-1}\right]$ & LSP $\left[\mu \mathrm{mol} \mathrm{m} \mathrm{s}^{-1}\right]$ & LCP $\left[\mu \mathrm{mol} \mathrm{m}^{-2} \mathrm{~s}^{-1}\right]$ \\
\hline GS1 & Initial (late May) & $7.415 \pm 0.435^{\mathrm{Aa}}$ & $525.033 \pm 28.987^{\mathrm{Aa}}$ & $15.371 \pm 3.020^{\mathrm{Aa}}$ \\
& Middle (late July) & $9.004 \pm 0.629^{\mathrm{Ba}}$ & $3,175.420 \pm 696.195^{\mathrm{Ba}}$ & $213.638 \pm 38.364^{\mathrm{Ba}}$ \\
CK & Initial (late May) & $6.875 \pm 0.324^{\mathrm{Aa}}$ & $523.221 \pm 30.981^{\mathrm{Aa}}$ & $12.567 \pm 3.023^{\mathrm{Aa}}$ \\
& Middle (late July) & $7.342 \pm 0.558^{\mathrm{Ab}}$ & $1,529.118 \pm 495.834^{\mathrm{Bb}}$ & $176.672 \pm 42.521^{\mathrm{Ba}}$ \\
\hline
\end{tabular}

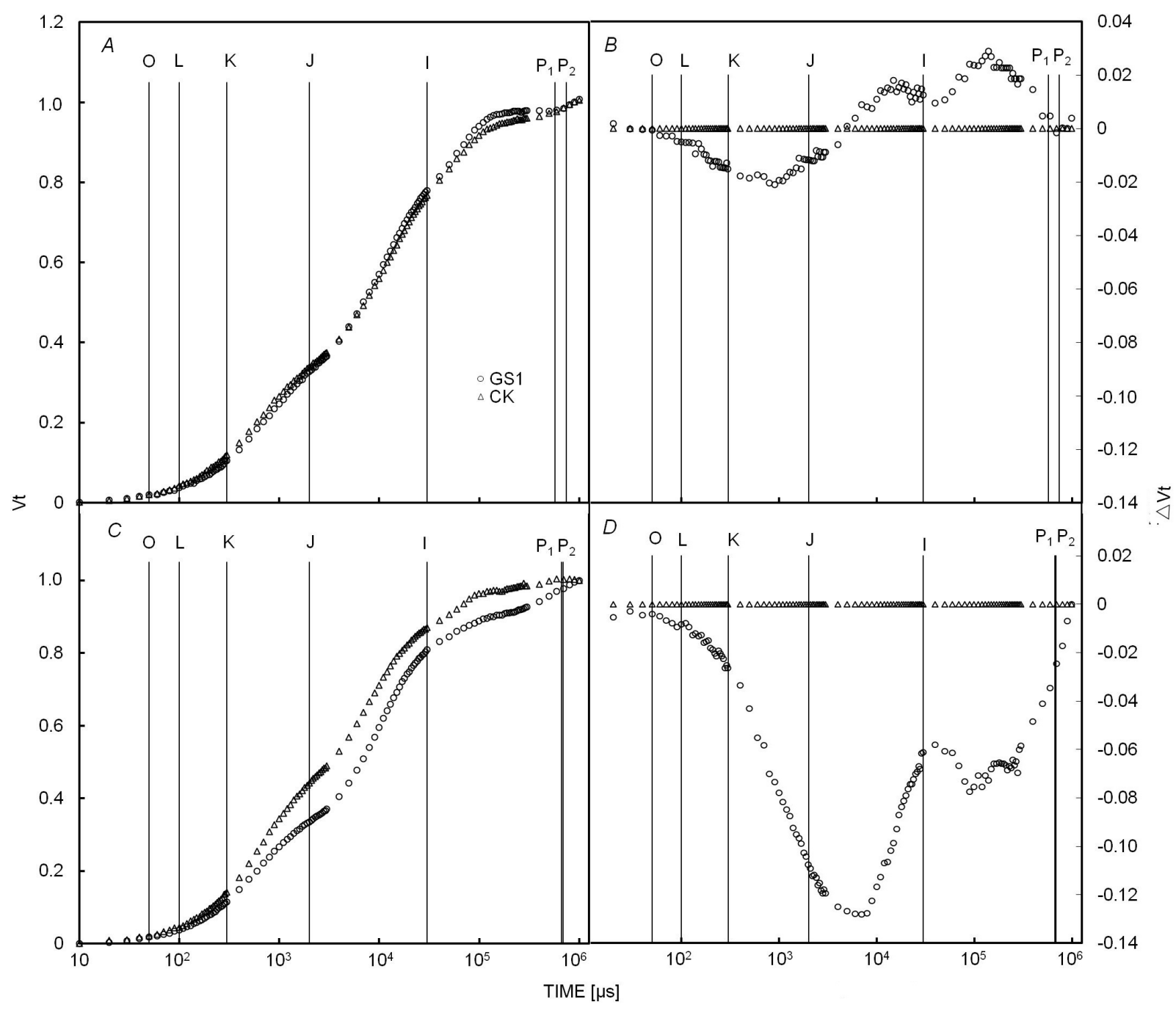

Fig. 3. Fast chlorophyll $a$ fluorescence curves of Pinus sylvestris var. mongolica clones 'GS1' and 'H524' (CK) at the initial $(A, B)$ and middle $(C, D)$ growth stages. $(A)$ and $(C)$ were plotted with the relative variable fluorescence $\left(\mathrm{V}_{\mathrm{t}}\right), \mathrm{V}_{\mathrm{t}}=\left(\mathrm{F}_{\mathrm{t}}-\mathrm{F}_{0}\right) /\left(\mathrm{F}_{\mathrm{m}}-\mathrm{F}_{0}\right)$. $(B)$ and $(D)$ were plotted with the fluorescence difference $\left(\Delta \mathrm{V}_{\mathrm{t}}\right), \Delta \mathrm{V}_{\mathrm{t}}=\mathrm{V}_{\mathrm{t}}(\mathrm{GS} 1)-\mathrm{V}_{\mathrm{t}}(\mathrm{CK}) . \mathrm{P}_{1}$ and $\mathrm{P}_{2}$ were the P-step points of CK and 'GS1', respectively.

It was visible from the traces of Fig. $3 A, C$ that the ratios of $\mathrm{J}: \mathrm{P}$ (the ratio of $\mathrm{V}_{t}$ in J-step to $\mathrm{V}_{t}$ in P-step) and $\mathrm{I}: \mathrm{P}$ (the ratio of $V_{t}$ in I-step to $V_{t}$ in P-step) increased in the CK as compared to 'GS1'. Fig. 3 also showed that the time of reaching the P-step ( $687 \mathrm{~ms}$ ) for ' $\mathrm{GS} 1$ ' was accelerated and substantially coincided with $\mathrm{CK}$.
Parameters of Chl $\boldsymbol{a}$ fluorescence: At the initial growth stage, absorption flux (ABS/RC), trapped energy flux $\left(\mathrm{TR}_{0} / \mathrm{RC}\right)$, electron transport flux $\left(\mathrm{ET}_{0} / \mathrm{RC}\right)$, and dissipate flux $\left(\mathrm{DI}_{0} / \mathrm{RC}\right)$ per $\mathrm{RC}$ of ' $\mathrm{GS} 1$ ' were not significantly different from those of $\mathrm{CK}$, and only the trapped energy flux $\left(\mathrm{TR}_{0} / \mathrm{CS}_{0}\right)$ and electron transport flux $\left(\mathrm{ET}_{0} / \mathrm{CS}_{0}\right)$ in cross 
section were slightly higher. However, the performance indexes $\left(\mathrm{PI}_{\mathrm{CSo}}, \mathrm{PI}_{\mathrm{CSm}}\right)$ based on $\mathrm{F}_{0}$ and $\mathrm{F}_{\mathrm{m}}$ were higher than those of $\mathrm{CK}$, although the performance index $\left(\mathrm{PI}_{\mathrm{ABS}}\right)$ based on absorption was similar to that of CK (Fig. 4). In addition, the normalized area $\left(\mathrm{S}_{\mathrm{m}}\right)$ and the number of times the $\mathrm{Q}_{\mathrm{A}}$ was reduced $(\mathrm{N})$ of ' $\mathrm{GS} 1$ ' were significantly higher than those of CK (1.58 and 1.57 times, respectively), and the time to reach the P-step $\left(\mathrm{T}_{\mathrm{fm}}, 741 \mathrm{~ms}\right)$ was relatively late (Figs. 3, 4).

As the initial growth stage, $\mathrm{ABS} / \mathrm{RC}$ and $\mathrm{TR}_{0} / \mathrm{RC}$ of 'GS1' at the middle growth stage were still not significantly different from those of CK. However, due to the significant increase in density of active reaction centers $\left(\mathrm{RC} / \mathrm{CS}_{0}\right)$ of 'GS1' (from 1,112.08 at the initial growth stage to 1,267.66 at the middle growth stage), energy flux per cross section $\left(\mathrm{ABS} / \mathrm{CS}_{0}, \mathrm{TR}_{0} / \mathrm{CS}_{0}, \mathrm{ET}_{0} / \mathrm{CS}_{0}, \mathrm{DI}_{0} / \mathrm{CS}_{0}\right)$ increased significantly. In addition, at the middle growth stage, the net closing rate of the reaction center (RC) at $100 \mu \mathrm{s}$ $\left(\mathrm{dVG} / \mathrm{dt}_{0}\right)$ and $300 \mu \mathrm{s}\left(\mathrm{dV} / \mathrm{dt}_{0}\right)$ of ' $\mathrm{GS} 1$ ' were smaller, and the energy dissipation ratio of electron passing through the $\mathrm{Q}_{\mathrm{A}}\left(\mathrm{V}_{\mathrm{j}}\right)$ was also smaller. Moreover, the ratio of the energy of electrons passing through the $\mathrm{Q}_{\mathrm{A}}{ }^{-}$to the energy captured at the $\mathrm{RC}\left(\psi_{\mathrm{E} 0}\right)$ and the quantum yield of electron transport from $\mathrm{Q}_{\mathrm{A}}^{-}$to $\mathrm{PQ}\left(\varphi_{\mathrm{E} 0}\right)$ were higher than those of CK (Fig. 4). The performance indexes $\left(\mathrm{PI}_{\mathrm{ABS}}, \mathrm{PI}_{\mathrm{CSo}}, \mathrm{PI}_{\mathrm{CSm}}\right)$ of ' $\mathrm{GS} 1$ ' were also significantly higher $(1.39,1.81$, and 1.91 times those of $\mathrm{CK}$, respectively). $\mathrm{S}_{\mathrm{m}}$ and $\mathrm{N}$ of ' $\mathrm{GS} 1$ ' were significantly higher than that of $\mathrm{CK}$, and the difference of the two indexes between two clones were almost the same as those at the initial growth stage (Fig. 4).

\section{Discussion}

Many studies on the diurnal variation of photosynthesis showed that the diurnal variation of $P_{\mathrm{N}}$ of most plants was bimodal, with the phenomenon of 'midday break', and the peak value in the morning was higher than that in the afternoon, whereas the diurnal variation of $P_{\mathrm{N}}$ in some plants was unimodal (Bassman and Zwier 1991, Li et al. 2006). In this study, it was found that 'GS1' was bimodal, and the first peak was higher than the second one. $\mathrm{T}_{\text {air }}, \mathrm{RH}$, and VPD had a great influence on the $P_{\mathrm{N}}$ of ' $\mathrm{GS} 1$ ', in which RH had a significantly positive correlation with $P_{\mathrm{N}}$, while $\mathrm{T}_{\text {air }}$ and VPD had significantly negative correlation. The results showed that higher $\mathrm{T}_{\text {air, }}$ and lower $\mathrm{RH}$ and higher VPD were responsible for the rapid decrease of $P_{\mathrm{N}}$ in 'GS1' at noon, and then $P_{\mathrm{N}}$ increased again in the afternoon with the adaptation to the environment. Previous studies have also shown that the ecological factors accounting for the 'midday break' phenomenon are mainly high temperature and low humidity at noon (He et al. 2004, Lin et al. 2006). Because 'H524' (CK) was not sensitive to the changes of the above three meteorological factors, although the $P_{\mathrm{N}}$ also showed a downward trend at noon, the change was relatively mild. In the afternoon, it remained unimodal and low level of $P_{\mathrm{N}}$, which was consistent with the diurnal $P_{\mathrm{N}}$ variation of ordinary $P$. sylvestris var. mongolica at the forest-forming stage in sandy land reported by Ding et al. (2011) and $\mathrm{Wu}$ et al. (2003).

There was a positive correlation between the $g_{\mathrm{s}}$ and $P_{\mathrm{N}}$ of 'GS1' and CK. The mean values of $P_{\mathrm{N}}$ and $g_{\mathrm{s}}$ of 'GS1' were significantly higher than those of CK, and it was suggested that the higher $g_{\text {s }}$ was the main reason for 'GS1' to maintain a higher $P_{\mathrm{N}}$. It was also found that there were differences in stomatal density (SD) and stomatal size between the two clones. The external and inner DS of 'GS1' were significantly higher than those of CK, which might be the structural factors for maintaining high $g_{s}$. Previous studies have also shown that stomatal density and size are controlled by quantitative trait loci (QTL), and there are differences between different genotypes of the same plant (Laza et al. 2010). Moreover, stomatal density and size tend to be positively correlated with physiological processes such as photosynthesis (Reich 1984, Muchow
A

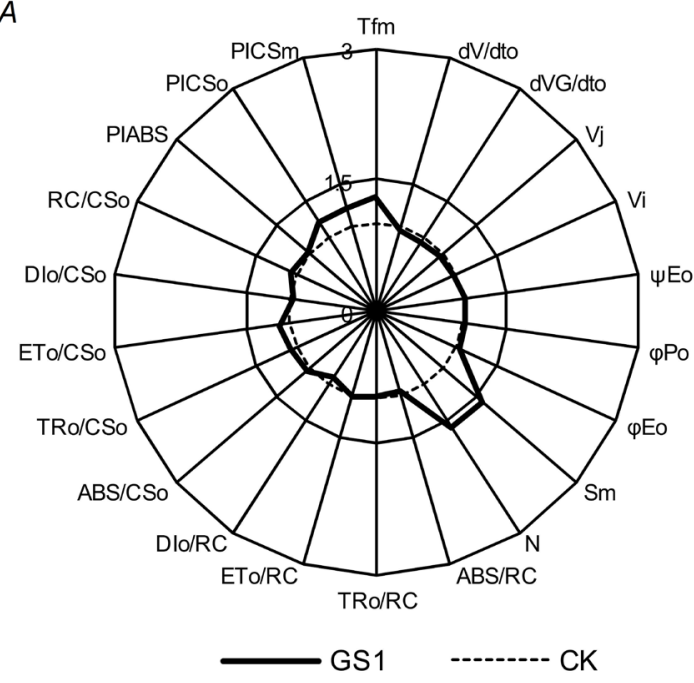

$B$

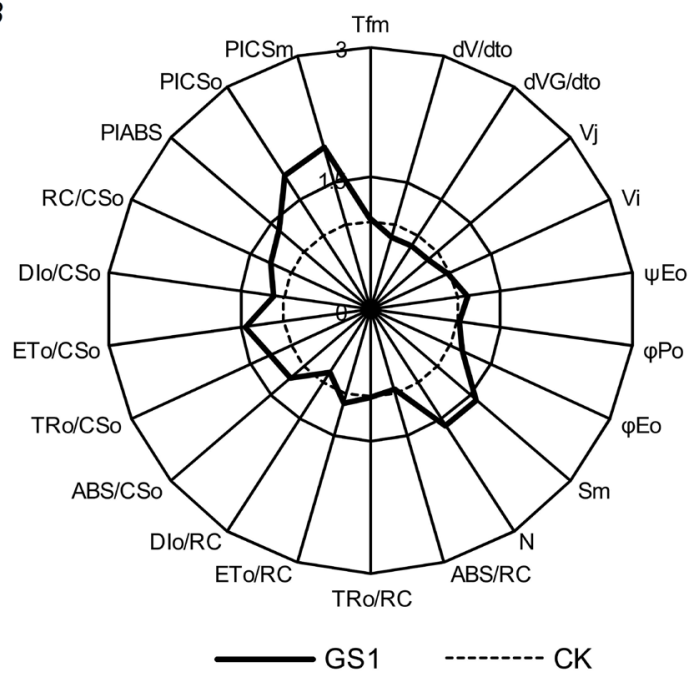

Fig. 4. Radar plot of fluorescence data of Pinus sylvestris var. mongolica clones 'GS1' and 'H524' $(\mathrm{CK})$ at the initial $(A)$ and middle $(B)$ growth stages. The parameters involved in the figure and their meanings are shown in Appendix. There are significant differences at 0.05 level in the parameters including $\mathrm{PI}_{\mathrm{ABS}}, \mathrm{PI}_{\mathrm{CS}}, \mathrm{PI}_{\mathrm{CSm}}, \mathrm{ABS} / \mathrm{CS}_{0}, \mathrm{TR}_{0} / \mathrm{CS}_{0}, \mathrm{ET}_{0} / \mathrm{CS}_{0}, \mathrm{DI}_{0} / \mathrm{CS}_{0}, \mathrm{DI}_{0} / \mathrm{RC}, \mathrm{ET}_{0} / \mathrm{RC}, \mathrm{dVG} / \mathrm{dt}_{0}, \mathrm{dV} / \mathrm{dt}_{0}, \mathrm{~V}_{\mathrm{j}}$, $\psi_{\mathrm{E} 0}, \varphi_{\mathrm{E} 0}, \mathrm{~S}_{\mathrm{m}}$, and $\mathrm{N}$ between the two clones at the middle growth stage. 
and Sinclair 1989). The light-response parameters further showed that $P_{\mathrm{Nmax}}$ of 'GS1' at the two growth stages was stronger than that of CK; especially the difference at the middle growth period was significant. At the initial growth stage, $P$. sylvestris var. mongolica always exhibits fast $\mathrm{TH}$ growth, while in the middle growth stage, it exhibits fast DBH growth (Gu et al. 2008). The photosynthetic capacity of 'GS1' at the middle growth stage was significantly higher than that of CK, and this was also why the DBH of 'GS1' was significantly higher than that of CK (Table 1). The better photosynthetic performance of ' $\mathrm{GS1}$ ' at the middle growth stage was due to the higher electron transport activity in the light reaction stage, demonstrated by the lower relative fluorescence intensity from O- to P-step. The deeper mechanism was that density of active reaction centers $\left(\mathrm{RC} / \mathrm{CS}_{0}\right)$ of ' $\mathrm{GS} 1$ ' increased significantly at the middle growth stage, resulting in a higher photochemical activity $\left(\mathrm{ABS} / \mathrm{CS}_{0}, \mathrm{TR}_{0} / \mathrm{CS}_{0}, \mathrm{ET}_{0} / \mathrm{CS}_{0}, \mathrm{DI}_{0} / \mathrm{CS}_{0}\right)$ in cross section. In addition, the net closing rate of $\mathrm{RC}$ at $100 \mu \mathrm{s}$ $\left(\mathrm{dVG} / \mathrm{dt}_{0}\right)$ and $300 \mu \mathrm{s}\left(\mathrm{dV} / \mathrm{dt}_{0}\right)$ of 'GS1' were smaller, and the energy dissipation ratio of electron passing through the $\mathrm{Q}_{\mathrm{A}}\left(\mathrm{V}_{\mathrm{j}}\right)$ was also smaller. Moreover, the ratio of the energy of electrons passing through the $\mathrm{Q}_{\mathrm{A}}^{-}$to the energy captured at the RC $\left(\psi_{\mathrm{E} 0}\right)$ and the quantum yield of electron transport from $\mathrm{Q}_{\mathrm{A}}^{-}$to $\mathrm{PQ}\left(\varphi_{\mathrm{E} 0}\right)$ were higher than those of CK. Under the combined action of the above indexes, the photosynthetic rate and photosynthetic performance indexes $\left(\mathrm{PI}_{\mathrm{ABS}}, \mathrm{PI}_{\mathrm{CSo}}, \mathrm{PI}_{\mathrm{CSm}}\right)$ of ' $\mathrm{GS} 1$ ' at the middle growth stage were significantly improved. The large number of $\mathrm{RC}$ and heat dissipation ratio in cross section $\left(\mathrm{DI}_{0} / \mathrm{CS}_{0}\right)$ of ' $\mathrm{GS} 1$ ' were also beneficial to the consumption of light energy that could be transformed into heat energy and lost, which ensured that 'GS1' has a higher LSP ( $>3,000$ $\mu \mathrm{mol} \mathrm{m} \mathrm{m}^{-2} \mathrm{~s}^{-1}$ ). If the excess light energy is not safely removed, it causes the accumulation of toxic substances in needles, thus destroying the photosynthetic apparatus (Quiles and López 2004). This study also found that the photosynthetic activity of ' $\mathrm{GS} 1$ ' at the middle growth stage was significantly higher than that at the initial growth stage (Fig. 1, Table 4), which was also mainly due to the increased number of RC. In Fig. 3, it is visible from the traces that the ratio of $\mathrm{J}: \mathrm{P}$ increased in the $\mathrm{CK}$ as compared to ' $\mathrm{GS} 1$ ', indicating an elevated reduction state of PQ pool (Tóth et al. 2007) and the elevated I:P might be related to retarded electron transport at the acceptor side of PSI, inactivation ferredoxin $\mathrm{NADP}^{+}$reductase and of the Calvin cycle (Stirbet et al. 2014); this is why the photochemical activity and photosynthetic capacity of $\mathrm{CK}$ were lower than those of 'GS1' at the middle growth stage.

At the same time, the O-J-I-P curve also showed that the time reaching P-step $\left(\mathrm{T}_{\mathrm{fm}}\right)$ of 'GS1' was slower than that of $\mathrm{CK}$ at the initial growth stage, but at the middle growth stage it was obviously accelerated, which coincided with that of CK. Our research also found that the normalized area of PQ pool $\left(\mathrm{S}_{\mathrm{m}}\right)$ of 'GS1' was larger at initial growth stage, leading to a big $T_{\text {fm }}$. $S_{m}$ of ' $G S 1$ ' was also larger at middle growth stage, but its energy flux per cross section significantly increased, thus it led to the acceleration of the arrival time of P-step, which basically coincided with $\mathrm{CK}$. The number of times the $\mathrm{Q}_{\mathrm{A}}$ was reduced $(\mathrm{N})$ of ' $\mathrm{GS} 1$ ' were higher than $\mathrm{CK}$ for both growing stages, which in turn indicated that it had larger PQ pool (Li et al. 2005).

Taken together, at both the initial and middle growth stages, there was a 'midday break' in the photosynthetic diurnal process in 'GS1'. The higher $\mathrm{T}_{\text {air }}$, lower $\mathrm{RH}$, and higher VPD at noon were the reasons for the 'midday break' of $P_{\mathrm{N}}$. The higher $g_{\mathrm{s}}$ of 'GS1' was the main reason why 'GS1' was able to maintain higher $P_{\mathrm{N}}$, while the larger external and inner DS were the structural factors for maintaining higher $g_{\mathrm{s}}$. At the middle growth stage, the higher $P_{\text {Nmax }}$ of ' $G S 1$ ' was mainly due to the increase in $\mathrm{RC} / \mathrm{CS}_{0}$, which resulted in the increase in photochemical activity $\left(\mathrm{ABS} / \mathrm{CS}_{0}, \mathrm{TR}_{0} / \mathrm{CS}_{0}, \mathrm{ET}_{0} / \mathrm{CS}_{0}, \mathrm{DI}_{0} / \mathrm{CS}_{0}\right)$ in cross section. The large amount of $\mathrm{RC}$ and high heat dissipation ratio $\left(\mathrm{DI}_{0} / \mathrm{CS}_{0}\right)$ of ' $\mathrm{GS} 1$ ' also ensured that it had higher LSP during the middle growth period.

\section{References}

Bassman J.H., Zwier J.C.: Gas exchange characteristics of Populus trichocarpa, Populus deltoides and Populus trichocarpa $\times$ P. deltoides clone. - Tree Physiol. 8: 145-159, 1991.

Blankenship R.E.: Molecular Mechanisms of Photosynthesis. $2^{\text {nd }}$ Edition. Pp. 312. Blackwell-John Wiley, Oxford 2014.

Demmig-Adams B., Adams III W.W.: The role of xanthophyll cycle carotenoids in the protection of photosynthesis. - Trends Plant Sci. 1: 21-26, 1996.

Ding X.G., He Q., Li J.Y. et al.: [The photosynthetic characteristics of Pinus sylvestris var. mongolica and Pinus tabulaeformis in Mu Us sandland.] - Res. Soil Water Conserv. 18: 215-219, 2011. [In Chinese]

Govindjee, Shevela D., Björn L.O.: Evolution of the Z-scheme of photosynthesis: a perspective. - Photosynth. Res. 133: 5-15, 2017.

Gu Z.B., Li C., Wang Q.H.: [Discussion on the relationship between growth rhythm and meteorological factors of Pinus sylvestris var. mongolica.] - Rur. Pra. Inf. Sci. Technol. 3: 52, 2008. [In Chinese]

Hari P., Hallman E., Salminen R., Vappavuori E.: Evaluation of factors controlling net photosynthetic rate in Scots pine seedlings under field conditions without water stress. Oecologia 48: 186-189, 1981.

He W.X., Yi J., Li H.M.: [Comparative study on daily change of photosynthesis rate of the rhizomatous grasses in milky ripe stage.] - Chin. J. Appl. Ecol. 15: 205-209, 2004. [In Chinese]

Kellomäki S., Wang K.Y.: Daily and seasonal $\mathrm{CO}_{2}$ exchange in Scots pine grown under elevated $\mathrm{O}_{3}$ and $\mathrm{CO}_{2}$ : experiment and simulation. - Plant Ecol. 136: 229-248, 1998.

Kiirats O., Kramer D.M., Edwards G.E.: Co-regulation of dark and light reactions in three biochemical subtypes of $\mathrm{C}_{4}$ species. - Photosynth. Res. 105: 89-99, 2010.

Krause G.H., Weis F.: Chlorophyll fluorescence and photosynthesis: the basics. - Annu. Rev. Plant Phys. 42: 313-349, 1991.

Laza M.R.C, Kondo M., Ideta O. et al.: Quantitative trait loci for stomatal density and size in lowland rice. - Euphytica 172: 149-158, 2010.

Li L., Lin L.S., Li X.Y., Lu Y.: Sensitivity of photosystem II activity in immature and mature leaves of desert sun plant Alhagi sparsifolia Shap. to light stress. - Acta Physiol. Plant. 37: 154-163, 2015.

Li P.M., Gao H.Y., Strasser R.J.: [Application of the fast chlorophyll fluorescence induction dynamics analysis in photosynthesis study.] - J. Plant Physiol. Mol. Biol. 31: 559566, 2005. [In Chinese] 
Li W.H., Wu W.X., Lu Z.M. et al.: [Analyses on introduction results of 4 tree species in genus Larix and diurnal photosynthetic changes.] - J. Southwest For. Coll. 26: 1-4, 2006. [In Chinese]

Lin B.H., Liu J.X., Xiao S.H., Yang Y.: [Diurnal change of photosynthetic characteristics of native Vetiveria zizanioides in Western Guangdong.] - Chin. J. Appl. Ecol. 17: 2041-2045, 2006. [In Chinese]

McGarvey R.C., Martin T.A., White T.L.: Integrating withincrown variation in net photosynthesis in loblolly and slash pine families. - Tree Physiol. 24: 1209-1220, 2004.

Mellander P.E., Bergh J., Lundmark T., Bishop K.: Recovery of photosynthetic capacity in Scots pine: a model analysis of forest plots with contrasting soil temperature. - Eur. J. For. Res. 127: 71-79, 2008.

Meng P., An Y.N., Bai X.F.: [Photosynthetic characteristics and chlorophyll $a$ fluorescence induction parameters of Pinus densiflora on sandy soil.] - Acta Ecol. Sin. 36: 3469-3478, 2016. [In Chinese]

Mereu S., Gerosa G., Marzuoli R. et al.: Gas exchange and JIPtest parameters of two Mediterranean maquis species are affected by sea spray and ozone interaction. - Environ. Exp. Bot. 73: 80-88, 2011.

Muchow R.C., Sinclair T.R.: Epidermal conductance, stomatal density and stomatal size among genotypes of Sorghum bicolor (L.) Moench. - Plant Cell Environ. 12: 425-431, 1989.

Ottander C., Campbell D., Öquist G.: Seasonal changes in photosystem II organisation and pigment composition in Pinus sylvestris. - Planta 197: 176-183, 1995.

Papageorgiou G.C., Govindjee: Chlorophyll a Fluorescence: A Signature of Photosynthesis. Advances in Photosynthesis and Respiration. Pp. 820. Springer, Dordrecht 2004.

Qiu N.W., Zhou F., Wang Y. et al.: [Comparison on characteristics of the fast chlorophyll fluorescence induction kinetics between Pinus species and Populus species.] - Sci. Silvae Sin. 49: 136-143, 2013. [In Chinese]

Quiles M.J., López N.I.: Photoinhibition of photosystems I and II induced by exposure to high light intensity during oat plant growth. - Plant Sci. 166: 815-823, 2004.

Reich P.B.: Leaf stomatal density and diffusive conductance in three amphistomatous hybrid poplar cultivars. - New Phytol. 98: 231-239, 1984.
Šiffel P., Šantrůček J.: Diurnal course of photochemical activity of winter-adapted Scots pine at subzero temperatures. Photosynthetica 43: 395-402, 2005.

Stirbet A., Govindjee: Chlorophyll $a$ fluorescence induction: a personal perspective of the thermal phase, the J-I-P rise. Photosynth. Res. 113: 15-61, 2012.

Stirbet A., Govindjee: On the relation between the Kautsky effect (chlorophyll $a$ fluorescence induction) and photosystem II: Basics and applications of the OJIP fluorescence transient. J. Photoch. Photobio. B 104: 236-257, 2011.

Stirbet A., Lazár D., Kromdijk J., Govindjee: Chlorophyll $a$ fluorescence induction: Can just a one-second measurement be used to quantify abiotic stress responses? - Photosynthetica $\mathbf{5 6}$ : 86-104, 2018.

Stirbet A., Riznichenko G.Yu, Rubin A.B., et al.: Modeling chlorophyll a fluorescence transient: relation to photosynthesis. - Biochemistry-Moscow+ 79: 291-323, 2014.

Strasser R.J., Tsimilli-Michael M., Srivastava A.: Analysis of the chlorophyll $a$ fluorescence transient. - In: Papageorgiou G.C., Govindjee (ed.): Chlorophyll $a$ Fluorescence: A Signature of Photosynthesis. Advances in Photosynthesis and Respiration. Pp. 321-362. Springer, Dordrecht 2004.

Tóth S.Z., Schansker G., Strasser R.J.: A non-invasive assay of the plastoquinone pool redox state based on the OJIPtransient. - Photosynth. Res. 93: 193-203, 2007.

Van Heerden P.D.R., Strasser R.J., Krüger G.H.J.: Reduction of dark chilling stress in $\mathrm{N}_{2}$-fixing soybean by nitrate as indicated by chlorophyll $a$ fluorescence kinetics. - Physiol. Plantarum 121: 239-249, 2004.

Wu C.R., Jin H.X., Yan Z.Z. et al.: [Average photosynthesis variation of Pinus sylvestris during a day in the arid and desert area.] - J. Arid Land Res. Environ. 6: 144-146, 2003. [In Chinese]

Zeliou K., Manetas Y., Petropoulou Y.: Transient winter leaf reddening in Cistus creticus characterizes weak (stresssensitive) individuals, yet anthocyanins cannot alleviate the adverse effects on photosynthesis. - J. Exp. Bot. 60: 30313042, 2009.

Zhang M., Wang H.J., Yu C.Q.: [The examination of high temperature stress of Ammopiptanthus mongolicus by chlorophyll fluorescence induction parameters.] - Ecol. Environ. Sci. 18: 2272-2277, 2009. [In Chinese]

Appendix. Chlorophyll $a$ fluorescence parameters.

\begin{tabular}{ll}
\hline Chlorophyll $a$ fluorescence parameters & Meaning \\
\hline Technical fluorescence parameters & \\
$\mathrm{S}_{\mathrm{m}}$ & Normalized area, representing the size of the plastoquinone pool \\
$\mathrm{T}_{\mathrm{fm}}$ & Time to reach P-step $\left(\mathrm{F}_{\mathrm{m}}\right)$ \\
$\mathrm{N}$ & The number of times the $\mathrm{Q}_{\mathrm{A}}$ was reduced during the period from the beginning of the \\
& illumination to the arrival of the $\mathrm{F}_{\mathrm{m}}$
\end{tabular}

Efficiencies and quantum yields

$\mathrm{V}_{\mathrm{j}}$

$\mathrm{V}_{\mathrm{i}}$

$\psi_{\mathrm{E} 0}=1-\mathrm{V}_{\mathrm{j}}$

$\varphi_{\mathrm{E} 0}=\varphi_{\mathrm{P} 0} \times \psi_{\mathrm{E} 0}$

$\varphi_{\mathrm{P} 0}=\mathrm{F}_{\mathrm{v}} / \mathrm{F}_{\mathrm{m}}$
Relative variable fluorescence intensity at the J-step, representing the energy dissipation ratio of electron passing through the $\mathrm{Q}_{\mathrm{A}}$

Relative variable fluorescence intensity at the I-step, representing the energy dissipation ratio of electron passing through the $\mathrm{Q}_{\mathrm{B}}$

The ratio of the energy of electrons passing through the $\mathrm{Q}_{\mathrm{A}}^{-}$to the energy captured at the reaction center

Quantum yield of electron transport from $\mathrm{Q}_{\mathrm{A}}^{-}$to $\mathrm{PQ}$

Maximum quantum yield of primary PSII photochemistry 
$\mathrm{dVG} / \mathrm{dt}_{0}$

$\mathrm{dV} / \mathrm{dt}_{0} \approx \mathrm{M}_{0}$

Specific energy fluxes (per active PSII)

$\mathrm{ABS} / \mathrm{RC}=\left(\mathrm{M}_{0} / \mathrm{V}_{\mathrm{j}}\right) / \varphi_{\mathrm{P} 0}$

$\mathrm{TR}_{0} / \mathrm{RC}=\mathrm{M}_{0} / \mathrm{V}_{\mathrm{j}}$

$\mathrm{ET}_{0} / \mathrm{RC}=\left(\mathrm{M}_{0} / \mathrm{V}_{\mathrm{j}}\right) \times \psi_{\mathrm{E} 0}$

$\mathrm{DI}_{0} / \mathrm{RC}=\mathrm{ABS} / \mathrm{RC}-\mathrm{TR}_{0} / \mathrm{RC}$

Phenomenological energy fluxes (per $\mathrm{CS}_{0}$ )

$\mathrm{ABS} / \mathrm{CS}_{0} \approx \mathrm{F}_{0}$

$\mathrm{RC} / \mathrm{CS}_{0}=(\mathrm{RC} / \mathrm{ABS}) \times\left(\mathrm{ABS} / \mathrm{CS}_{0}\right)$

$\mathrm{TR}_{0} / \mathrm{CS}_{0}=\left(\mathrm{TR}_{0} / \mathrm{ABS}\right) \times\left(\mathrm{ABS} / \mathrm{CS}_{0}\right)$

$\mathrm{ET}_{0} / \mathrm{CS}_{0}=\left(\mathrm{ET}_{0} / \mathrm{ABS}\right) \times\left(\mathrm{ABS} / \mathrm{CS}_{0}\right)$

$\mathrm{DI}_{0} / \mathrm{CS}_{0}=\left(\mathrm{DI}_{0} / \mathrm{ABS}\right) \times\left(\mathrm{ABS} / \mathrm{CS}_{0}\right)$

Performance indexes

$\mathrm{PI}_{\mathrm{ABS}}=(\mathrm{RC} / \mathrm{ABS}) \times\left[\varphi_{\mathrm{P} 0} /\left(1-\varphi_{\mathrm{P} 0}\right)\right] \times$ $\left[\psi_{\mathrm{E} 0} /\left(1-\psi_{\mathrm{E} 0}\right)\right]$

$\mathrm{PI}_{\mathrm{CSo}}=\mathrm{PI}_{\mathrm{ABS}} \times\left(\mathrm{ABS} / \mathrm{CS}_{0}\right)$

$\mathrm{PI}_{\mathrm{CSm}}=\mathrm{PI}_{\mathrm{ABS}} \times\left(\mathrm{ABS} / \mathrm{CS}_{\mathrm{m}}\right)$
Net closing rate of reaction center at $100 \mu \mathrm{s}$

Net closing rate of reaction center at $300 \mu \mathrm{s}$

Absorption flux (of antenna Chls) per RC

Trapped energy flux (leading to $\mathrm{Q}_{\mathrm{A}}$ reduction) per $\mathrm{RC}$

Electron transport flux (further than $\mathrm{Q}_{\mathrm{A}}^{-}$) per $\mathrm{RC}$

Dissipate flux per RC

(C) The authors. This is an open access article distributed under the terms of the Creative Commons BY-NC-ND Licence. 